\title{
Socioeconomic inequalities in dementia risk among a French population-based cohort: quantifying the role of cardiovascular health and vascular events
}

\author{
Noémie Letellier ${ }^{1}$ (D) S Sindana D. Ilango ${ }^{2,3} \cdot$ Marion Mortamais $^{1} \cdot$ Christophe Tzourio $^{4} \cdot$ Audrey Gabelle $^{1,6}$. \\ Jean-Philippe Empana ${ }^{5}$. Cécilia Samieri ${ }^{4}$. Claudine Berr ${ }^{1,6} \cdot$ Tarik Benmarhnia $^{3,7}$
}

Received: 8 April 2021 / Accepted: 8 July 2021 / Published online: 25 July 2021

(c) The Author(s) 2021

\begin{abstract}
This study aimed to investigate the role of cardiovascular health $(\mathrm{CVH})$ and vascular events as potential contributors to socioeconomic inequalities in dementia using causal mediation analyses. We used data from the Three-City Cohort, a French population-based study with 12 years of follow-up, with active search of dementia cases and validated diagnosis. Individual socioeconomic status was assessed using education, occupation and income. A CVH score as defined by the American Heart Association and incident vascular events were considered separately as mediators. We performed multi-level Cox proportional and Aalen additive hazard regression models to estimate the total effects of socioeconomic status on dementia risk. To estimate natural direct and indirect effects through $\mathrm{CVH}$ and vascular events, we applied two distinct weighting methods to quantify the role of CVH and vascular events: Inverse Odds Ratio Weighting (IORW) and Marginal Structural Models (MSM) respectively. Among 5581 participants, the risk of dementia was higher among participants with primary education (HR 1.60, 95\%CI 1.44-1.78), blue-collar workers (HR 1.62, 95\% CI 1.43-1.84) and with lower income (HR 1.23, 95\%CI 1.09-1.29). Using additive models, 571 (95\% CI 288-782) and 634 (95\% CI 246-1020) additional cases of dementia per 100000 person and year were estimated for primary education and blue-collar occupation, respectively. Using IORW, the CVH score mediate the relationship between education or income, and dementia (proportion mediated $17 \%$ and 26\%, respectively). Yet, considering vascular events as mediator, MSM generated indirect effects that were smaller and more imprecise. Socioeconomic inequalities in dementia risk were observed but marginally explained by $\mathrm{CVH}$ or vascular events mediators.
\end{abstract}

Keywords Cardiovascular health $\cdot$ Dementia $\cdot$ Mediation analysis $\cdot$ Socioeconomic status $\cdot$ Social determinants

Noémie Letellier

nletellier@ucsd.edu

1 Institute for Neurosciences of Montpellier INM, Univ Montpellier, INSERM, Montpellier, France

2 School of Public Health, San Diego State University, San Diego, CA, USA

3 Herbert Wertheim School of Public Health, University of California San Diego, La Jolla, CA, USA

4 Université de Bordeaux, INSERM, Bordeaux Population Health Research Center, UMR 1219, Bordeaux, France

5 Université de Paris, INSERM U970, Paris Cardiovascular Research Center, Paris, France

6 Memory Research and Resources Center, Department of Neurology, Montpellier University Hospital Gui de Chauliac, Montpellier, France

7 Scripps Institution of Oceanography, University of California, San Diego, La Jolla, CA, USA

\section{Introduction}

Low socioeconomic status (SES), measured through education, occupation or income, is an important determinant of various health outcomes [1] including premature mortality [2]. The inequalities in health related to SES have been rising in the European Union and in most countries, and one of the major challenges is to understand their modifiable mechanisms to reduce inequalities through equitable interventions [3, 4].

Low SES has been associated with late-life cognitive impairment [5], higher risk of dementia [6], Alzheimer's Disease [7], and dementia-related death [8]. In the ThreeCity (3C) Study, a large French cohort, SES was associated with risk of dementia [9] and premature death [10]. The impact of SES on cognitive ageing exists at different lifecourse periods, from childhood to older ages. In France, 
a socioeconomic gradient in cognitive impairment was highlighted from middle-aged [11]. Recently, associations between life-course SES and late-life memory function and decline were underlined [5, 12, 13]. Moreover, early life conditions could have an effect on structural brain development, an association between childhood SES and hippocampal volumes in late life was highlighted [14].

Understanding mediating pathways can improve our understanding of the underlying mechanism through which SES influences risk of dementia. SES-dementia relationship can be partly explained by modifiable health conditions and lifestyle factors [15], and identifying and quantifying the role of actionable mechanisms is critical given the lack of existing treatments potentially altering the clinical course of dementia [16] in an aging population.

In this context, cardiovascular health $(\mathrm{CVH}-\mathrm{a}$ 7-item tool from the American Heart Association AHA including smoking, body mass index, physical activity, diet, total cholesterol, blood pressure, fasting glucose) and cardiovascular diseases (CVD) could be relevant mediators in the SES-dementia relationship. SES inequalities were consistently reported in studies of CVH [17] and CVD [18-20]. Furthermore, cardio-metabolic risk factors (high blood pressure, dyslipidemia, obesity, diabetes) have been associated with early alterations of brain structure and metabolism [21-23] and are risk factors for cognitive decline and dementia [24]. In the 3C Study, ideal CVH was associated with decreased risk of dementia [25]. Conversely, incident coronary heart disease and stroke were associated with an increased risk of dementia [26, 27].

To our knowledge, only two studies investigated modifiable risk factors as potential mediators in the relationship between SES and dementia. In the Toyama Dementia Survey in Japan, a cross-sectional study, lifestyle-related diseases such as diabetes minimally acted as a mediator between low education attainment and dementia [28]. In the English Longitudinal Study of Ageing (ELSA), a mediation analysis shown that $52 \%$ of the dementia risk difference between the highest and lowest wealth tertile was mediated by differences in 'LIfestyle for BRAin health' (LIBRA) score [29].

Causal mediation analyses can provide a better understanding of complex relationships quantifying the importance of each pathway and thereby allowing to identify potential prevention targets to successful ageing. The objective of this study was to quantify the contribution of $\mathrm{CVH}$ and vascular events in the socioeconomic inequalities in dementia risk over 12 years, in a large French cohort. We employed a causal mediation framework and used different decomposition approaches including weighting methods with inverse odds ratio weighting and marginal structural models.

\section{Methods}

\section{Study population}

We used data from the 3C Study, a cohort of 9294 noninstitutionalized participants aged 65 or over enrolled from the electoral rolls of three French cities (Bordeaux, Dijon and Montpellier) in 1999-2001. The main objective of the 3C Study was to assess the risk of dementia and cognitive impairment related to vascular factors [30]. Each participant signed an informed consent. The study protocol was approved by The Ethics Committees of the Hospital of Kremlin-Bicêtre and Sud-Méditerranée III.

We restricted the population to participants with results of a baseline blood draw or data from the questionnaire, without prevalent dementia or history of cardiovascular diseases at baseline, with follow-up for dementia, and without missing information on SES and incident vascular events (Figure S1).

\section{Socioeconomic status (SES)}

Individual SES was evaluated by level of education (primary/secondary and higher [secondary, high school and university], occupational category (blue collars/white collars) and monthly household income (based on the categories of the questionnaire: $<1500 € / \geq 1500 €$, i.e. $\$ 1800$ ).

\section{Ascertainment of cardiovascular health, coronary heart disease and stroke}

The CVH score, evaluating the level of $\mathrm{CVH}$ at baseline, was calculated previously [25] according to the following 7-item proposed by the AHA [31]: smoking, physical activity, healthy diet, body mass index, total cholesterol, blood pressure, and fasting plasma glucose. It was calculated by assigning 0 point for each metric at poor level, 1 point for each metric at intermediate level, and 2 points for each metric at recommended optimal level (total score range, 0-14). For our mediation analyses, CVH score was used as a continuous variable, and each previous item was assessed individually.

The survey of Coronary Heart Disease (CHD) and stroke occurrence during follow-up has been described previously $[32,33]$. All suspected incident cases of CHD and stroke were documented by two independent expert committees. CHD included a definite hospitalized angina, hospitalized myocardial infarction, coronary balloon dilatation, arterial bypass or CHD death. Stroke was defined according to the criterion of the World Health Organization. Our analysis was restricted to non-fatal incident CHD and stroke events 
until the year 2010 (the last visit with validation of vascular events in the cohort).

\section{Diagnosis of dementia}

At baseline and at each follow-up visit, cognitive function was assessed by a trained psychologist using neuropsychological tests (Mini-Mental State Examination, the Isaacs Set Test and the Benton Visual Retention Test). At each followup visit, based on neuropsychological performances, neurologists examined participants with suspected dementia to establish a provisional diagnosis [30]. Diagnosis of dementia was then reviewed and validated by an independent committee of neurologists according to the DSM-IV criteria. For the present analyses, we considered all incident cases of allcause dementia over the 12-year follow-up.

\section{Statistical analyses}

The baseline characteristics of study population were described with median (interquartile range) and frequencies (\%). To estimate the Total Effect (TE) of SES on incident dementia, we fit a Cox proportional hazards model and an Aalen additive hazards model for each of the three SES indicators with age as the time scale $[34,35]$.

\section{Accounting for selective entry into sample analyzed and censoring during follow-up}

Participants excluded from the analytical sample at baseline were older, more often men, with a lower level of education, a lower income, more often blue-collar workers and living in poorer neighborhoods. To minimize the possibility of selection bias, we estimated the inverse of the probability of an individual being censored at baseline using logistic regression, conditional on baseline covariates (age at baseline, sex, centre, education level, APOE genotype, alcohol intake, smoking habits, diabetes, history of vascular pathology, history of respiratory pathology, and neighborhood characteristics). In addition, we calculated an inverse probability of censoring weights (IPCW) to consider informed attrition (including death as a competing event, withdrawal, and lost to follow-up). Each participant was assigned a weight to consider participants who are underrepresented in the analytical data (see Figure S2 and Figure S3). For all analyses, we thus used inverse probability of censoring weighted models to consider both potential differential informed censoring at baseline and during follow-up [36].

\section{Causal mediation analyses}

To identify if CVH score or incident vascular events (CHD and stroke) were an intermediate between SES-dementia relationship, we conducted causal mediation analyses using the potential outcome framework considering each SES indicator (education, income and occupation) separately [37].

We decomposed the total effect of SES-dementia inequalities into direct effect and indirect effect through $\mathrm{CVH}$ or vascular events. We let $\mathrm{X}_{\mathrm{i}}$ be the SES exposure $i$ (education, income or occupation), $\mathrm{M}_{\mathrm{n}}$ the potential mediators $n(\mathrm{CVH}$ or incident vascular events), and $\mathrm{Y}$ the outcome (incident dementia). In this context, we interpreted the total effect (TE) as the amplitude of SES inequalities in dementia, both directly and through cardiovascular intermediates. The natural direct effect (NDE) is interpreted as the expected level of SES inequality in dementia if the whole population was assigned the mediator status (i.e., $\mathrm{CVH}$ or vascular events) of the highest SES group. The natural indirect effect (NIE) represents the change in dementia risk when a given SES indicator is set to the lowest value (e.g., low education) and the mediator changes (e.g., from yes to no vascular events) to what it would have been for the same contrast in the other SES category (e.g., high education). We also tested for the presence of an interaction between each $X_{i}$ and $M_{n}$. The estimation of natural effects is suited for describe the underlying mechanisms of the observed relationship between SES and dementia [38, 39].

To decompose the TE into the part that is explained by $\mathrm{CVH}$ score or vascular events (NIE) and the part that is due to other factors (NDE), we decomposed this effect into its direct and indirect effect by fitting two models: a mediator and an outcome model. We included the following covariates in the models: sex, educational level (when the exposure was not education), apolipoprotein Eع4 (APOE\&4) carrier status and study centers. When the exposure was income, we also adjusted for living alone (yes/no). We considered spatial clustering by incorporating census commune level (municipality) as a random effect for the intercept. TEs, DEs, and IEs and their 95\% confidence intervals were estimated via bootstrapping using 1000 independent replications. We calculated proportions mediated (PM in \%) as follows: $\left[\mathrm{HR}^{\mathrm{NDE}}\right.$ $\left.\left(\mathrm{HR}^{\mathrm{NIE}}-1\right) /\left(\mathrm{HR}^{\mathrm{NDE}} \times \mathrm{HR}^{\mathrm{NIE}}-1\right)\right]$.

We considered as identification assumptions for the interpretation for TE, NDE and NIE, that there were no unmeasured confounders and no exposure-mediator interaction. We also tested for possible interactions between each SES and gender and APOE genotype.

We used two different decomposition approaches to consider the two mediators of interests separately while accounting for their dependence (i.e., CVH affecting vascular events): Inverse Odds Ratio Weighting (IORW) and Marginal Structural Models (MSM).

First, to study CVH score as mediator and decompose the CVH score into this biological and behavioral components, we used Inverse Odds Ratio Weighting (IORW) [40]. IORW condenses information on the odds ratio between 
treatment and mediators, conditional on covariates, into a weight. This weight, the inverse exposure-mediator odds ratio given covariates, is then used to estimate natural direct effects via weighted regression analysis. Then, indirect effects are identified by subtracting direct effects from total effects [41]. Such approach is particularly well fitted when multiple mediators are considered simultaneously by capitalizing on the odds ratio's invariance property.

Second, to estimate TE, NDE, NIE of SES through incident vascular events, we used MSM with inverse probability weighting (IPW) as recommended in the presence of multiple mediators that are dependent [42]. Indeed, in our setting, $\mathrm{CVH}$ is a precursor of incident vascular events and can thus be considered as confounder between vascular events and dementia that is itself induced by the SES exposures of interest. As traditional mediation analyses typically fail in such settings, we employed a MSM to overcome such limitations. In these analyses (with vascular events as the mediator of interest), we considered $\mathrm{CVH}$ as a continuous score in the weight calculation. Analyses were performed with SAS 9.4 and RStudio Version 3.6.0.

\section{Results}

\section{Study population}

Finally, 5581 subjects without dementia and history of vascular disease at baseline and with complete data were included (for a total of 45,396 person-years). Approximately $9 \%$ of participants $(n=515)$ developed dementia during this 12 year-period, corresponding to an annual incidence rate of $11.3 / 1000$ person-years. The median age at enrollment was 73 years and $63 \%$ were women.

The mean of the CVH score at baseline was higher among participants without incident vascular events (8.2 [SD 1.8] VS 7.6 [SD 1.9] among those with incident vascular events).

In comparison to people without dementia, people who developed dementia were older and more often women (Table 1). They had poorer cardiovascular health, with a mean (SD) CVH score of 7.8 (2.0) (vs. 8.2 [1.8]) and had higher rate of incident vascular events (11.5 vs. 7 ).

\section{Total effect of SES on dementia risk}

Participants with primary education level had a greater risk of dementia than those with secondary or higher education level (adjusted HR 1.60, 95\% CI 1.44-1.78) (Table 2). The risk of developing dementia was higher among blue-collar than white-collar workers, with an adjusted HR of $1.62(95 \%$ CI 1.43-1.84). Lower income was associated with a higher risk of dementia (adjusted HR 1.23, 95\% CI 1.09-1.39). When using additive models, 571 (95\% CI 269-873), 634
Table 1 Individual characteristics of study population according to dementia status $(\mathrm{N}=5581)$

\begin{tabular}{|c|c|c|}
\hline Individual characteristics, $\mathrm{n}(\%)$ & $\begin{array}{l}\text { Non-demented } \\
(\mathrm{n}=5066)\end{array}$ & $\begin{array}{l}\text { Demented } \\
(\mathrm{n}=515)\end{array}$ \\
\hline Age $(\text { years })^{\mathrm{a}}$ & $72.4(69.0-76.5)$ & $75.6(72.0-79.5)$ \\
\hline Women & $3161(62.4)$ & $352(68.3)$ \\
\hline \multicolumn{3}{|l|}{ Study center } \\
\hline Bordeaux & $902(17.8)$ & $150(29.1)$ \\
\hline Dijon & $2869(56.6)$ & $247(48.0)$ \\
\hline Montpellier & $1295(25.6)$ & $118(22.9)$ \\
\hline Primary education & $1109(21.9)$ & $163(31.7)$ \\
\hline Lower income & $1718(33.9)$ & $216(41.9)$ \\
\hline Blue-collar workers & $797(15.7)$ & $114(22.1)$ \\
\hline APOEE4 carrier & $939(18.5)$ & $138(26.8)$ \\
\hline $\mathrm{CVH}_{\text {score }}{ }^{\mathrm{b}}$ & $8.2(1.8)$ & $7.8(2.0)$ \\
\hline Incident vascular events & $357(7.0)$ & $59(11.5)$ \\
\hline
\end{tabular}

CVH Cardiovascular Health

${ }^{a}$ median (interquartile range)

${ }^{\mathrm{b}}$ mean (SD) [total score range, 0-14]

(95\% CI 246-1020) and 221 (95\% CI - 79-521) additional cases of dementia per 100000 person and year were estimated for primary education, blue-collar occupation and lower income respectively (Table 2).

\section{Mediation analyses}

The results of mediation analyses considering CVH score as mediator using IORW are reported on Table 3. When decomposing the TE into NDE and NIE for education, we observed a direct effect HR of 1.51 (95\% CI 1.22-1.88) and an indirect effect HR of 1.08 (95\% CI 1.03-1.14) mediated through $\mathrm{CVH}$ score, these resulting to $17 \%$ (i.e., PM) of the effect of education on dementia being mediated through $\mathrm{CVH}$. When we decomposed the CVH score into biological and behavioral components, behavioral components appeared to more contribute to socioeconomic inequalities in dementia (e.g., with the alimentation component, we observed an indirect effect HR of 1.04 (95\% CI 0.99-1.09)). For occupation, we found a direct effect HR of 1.64 (95\% CI 1.24-2.17) and an indirect effect HR of 1.00 (95\% CI 0.93-1.08) mediated through CVH score. For income, we observed a direct effect HR of 1.19 (95\% CI 0.94-1.51) and an indirect effect HR of 1.05 (95\% CI 1.00-1.11) corresponding to a PM of $26 \%$. For occupation and income, we found that none of the $\mathrm{CVH}$ score components appeared to contribute appreciably to socioeconomic inequalities in dementia (Table 3).

The results of MSM when considering vascular events as mediator are in line with these findings, even if the indirect effects were weaker and less precise for all socioeconomic indicators (Table 4). 
Table 2 Total effects of socioeconomic level on dementia risk (Weighted Cox proportional hazards model and Aalen model ${ }^{\mathrm{a}}, \mathrm{N}=5581$ )

\begin{tabular}{|c|c|c|c|c|c|}
\hline & \multirow{2}{*}{$\begin{array}{l}\text { All-type incident } \\
\text { dementia }(\mathrm{n}=515) \\
\mathrm{n},(\%)\end{array}$} & \multicolumn{2}{|c|}{ Cox PH model } & \multicolumn{2}{|c|}{ Aalen model } \\
\hline & & HR & $(95 \% \mathrm{CI})$ & Estimate & $(95 \% \mathrm{CI})$ \\
\hline \multicolumn{6}{|l|}{ Educational level } \\
\hline Secondary or higher & $352 / 4309(8.2)$ & ref & - & & \\
\hline Primary & $163 / 1272(12.8)$ & 1.60 & $(1.44-1.78)$ & $571 \times 10^{-5}$ & $\left(269 \times 10^{-5}-873 \times 10^{-5}\right)$ \\
\hline \multicolumn{6}{|l|}{ Occupational category } \\
\hline White-collar & $401 / 4670(8.6)$ & ref & - & & \\
\hline Blue-collar & $114 / 911(12.5)$ & 1.62 & $(1.43-1.84)$ & $634 \times 10^{-5}$ & $\left(246 \times 10^{-5}-1020 \times 10^{-5}\right)$ \\
\hline \multicolumn{6}{|l|}{ Income $(n=5570)$} \\
\hline Higher income & 299/3647 (8.2) & ref & - & & \\
\hline Lower income & 216/1934 (11.2) & 1.23 & $(1.09-1.39)$ & $221 \times 10^{-5}$ & $\left(-79 \times 10^{-5}-521 \times 10^{-5}\right)$ \\
\hline
\end{tabular}

$H R$ hazard ratio; PH: Proportional Hazard; $C I$ confidence interval

${ }^{a}$ Adjusted for age, gender, education (for income and occupation models), living alone (for income models), APOE4 and study centers

\section{Discussion}

Using data from the 3C Study, a French population-based cohort of 5581 individuals, we decomposed the total effect of SES on incident dementia into direct and indirect effects through cardiovascular health level (CVH score) and incident vascular events (CHD and stroke). The risk of dementia was higher among participants who were blue-collar workers, with a lower educational level or income. Based on the IORW, we found an indirect effect through $\mathrm{CVH}$ and vascular events for two of these socioeconomic measures (17\% for education and $26 \%$ for occupation). However, we did not identify strong and precise indirect effects of $\mathrm{CVH}$ and vascular events using weighting decomposition approaches. Overall, we conclude that CVH and vascular events may play a minor role in explaining SES inequalities in the risk of dementia in this study population.

Conceptualizing SES variables as exposures of interest in epidemiological research under the potential outcomes framework has been shown to be a challenging task given the likely violation of the consistency assumption [43]. Consistency, in causal inference, requires that there be a single version of exposure under study and that this version of exposure, as recorded in the data, be the same version of exposure across exposed individuals. For SES variables such as education or income, it has been shown that such assumption is often violated [44] as many pathways between each SES and health are possible. Instead, in our study we rather conceptualized a specific pathway (i.e., cardiovascular) linking each SES variable of interest to dementia risk and aimed at decomposing specific $\mathrm{CVH}$ and vascular events pathways that contribute to explain inequalities in dementia risk. In this context, the decomposition analyses allowed us to isolate a specific pathway and provide some potentially useful etiological insights about the appropriateness of strategies focusing in $\mathrm{CVH}$ to potentially reduce dementia
SES disparities. For example, lifestyle interventions could be implemented to improve CVH (e.g., reduced obesity, diabetes, hypertension in midlife, physical exercise, smoking cessation) targeting low SES groups in order to reduce dementia related SES inequalities, particularly through healthy diet who seems to have a more important role than the other CVH components to explain education-dementia inequalities.

The total effects of SES variables on dementia incidence are in line with previous studies [5-8]. The SES may act through brain reserve capacity and lifelong mental stimulation or other plausible midlife factors that may be mediators such as health behaviors, living conditions, or access to health care. Moreover, SES may influence brain structure and function [45], for example SES can affect the functional development of the prefrontal regions from early childhood [46]. Thus, social inequalities in cognition may be the result of both complex biological mechanisms and socially constructed determinants. Previously, an indirect effect of lifestyle-related diseases in the relationship between SES and dementia was found in the Toyama Dementia Survey in Japan [28] and the ELSA cohort in English population [29]. In the study by Kay et al. [29], they found a larger proportion mediated than in our study. Such discrepancy may be mostly explained by the difference in the number of dementia cases (only 92 cases representing 3.0\% in ELSA), the diagnosis of dementia (base on self-reported measures in ELSA) and different age distribution (mean age: 64.9 years vs 73 years in the 3C Study).

Our findings regarding small indirect effects for $\mathrm{CVH}$ and vascular events in SES-dementia inequalities could be related to the characteristics of our cohort. Due to exclusion of prevalent cases of CVD and potentially the most exposed individuals, the mediation may be underestimated. Moreover, our population of interest is relatively old, and we thus focused on potential changes in CVD and $\mathrm{CVH}$ at later ages. 
Table 3 Total, direct and indirect effects of socioeconomic level through $\mathrm{CVH}$ score in binary and each component (using IORW , $\mathrm{N}=5581)$

\begin{tabular}{|c|c|c|c|c|c|c|}
\hline & \multicolumn{2}{|c|}{ Total effect } & \multicolumn{2}{|c|}{$\begin{array}{l}\text { Natural direct } \\
\text { effect }\end{array}$} & \multicolumn{2}{|c|}{$\begin{array}{l}\text { Natural indirect } \\
\text { effect }\end{array}$} \\
\hline & HR & $(95 \% \mathrm{CI})$ & HR & $(95 \% \mathrm{CI})$ & HR & $(95 \% \mathrm{CI})$ \\
\hline \multicolumn{7}{|l|}{ Primary education } \\
\hline CVH score s $^{b}$ & 1.62 & [1.32-1.99] & 1.51 & {$[1.22-1.88]$} & 1.08 & [1.03-1.14] \\
\hline \multicolumn{7}{|l|}{ Components of CVH score } \\
\hline Biological components & 1.62 & [1.32-1.99] & 1.61 & [1.31-1.99] & 1.01 & {$[1.00-1.02]$} \\
\hline Behavioral components & 1.62 & [1.32-1.99] & 1.60 & {$[1.30-1.98]$} & 1.01 & [0.99-1.04] \\
\hline \multicolumn{7}{|l|}{ Biological components } \\
\hline Total cholesterol & 1.62 & [1.32-1.99] & 1.62 & [1.32-1.99] & 1.00 & {$[0.99-1.01]$} \\
\hline Blood pressure & 1.62 & {$[1.32-1.99]$} & 1.60 & {$[1.30-1.95]$} & 1.01 & {$[1.00-1.03]$} \\
\hline Fasting plasma glucose & 1.62 & [1.32-1.99] & 1.61 & {$[1.31-1.98]$} & 1.01 & {$[1.00-1.02]$} \\
\hline \multicolumn{7}{|l|}{ Behavioral components } \\
\hline Smoking & 1.62 & [1.32-1.99] & 1.66 & {$[1.35-2.03]$} & 0.98 & {$[0.94-1.00]$} \\
\hline Healthy diet & 1.62 & [1.32-1.99] & 1.56 & {$[1.26-1.94]$} & 1.04 & {$[0.99-1.09]$} \\
\hline Physical activity & 1.62 & [1.32-1.99] & 1.63 & [1.33-1.99] & 1.00 & {$[0.98-1.01]$} \\
\hline BMI & 1.62 & [1.32-1.99] & 1.61 & {$[1.31-2.00]$} & 1.01 & {$[0.97-1.05]$} \\
\hline \multicolumn{7}{|l|}{ Blue collar workers } \\
\hline CVH score ${ }^{b}$ & 1.64 & [1.25-2.11] & 1.64 & [1.24-2.17] & 1.00 & {$[0.93-1.08]$} \\
\hline \multicolumn{7}{|l|}{ Components of CVH score } \\
\hline Biological components & 1.64 & {$[1.25-2.11]$} & 1.64 & {$[1.25-2.12]$} & 1.00 & {$[0.99-1.02]$} \\
\hline Behavioral components & 1.64 & {$[1.25-2.11]$} & 1.64 & {$[1.26-2.12]$} & 1.00 & {$[0.96-1.04]$} \\
\hline \multicolumn{7}{|l|}{ Biological components } \\
\hline Total cholesterol & 1.64 & {$[1.25-2.11]$} & 1.64 & {$[1.25-2.11]$} & 1.00 & {$[0.98-1.01]$} \\
\hline Blood pressure & 1.64 & {$[1.25-2.11]$} & 1.63 & [1.23-2.09] & 1.01 & {$[0.99-1.03]$} \\
\hline Fasting plasma glucose & 1.64 & {$[1.25-2.11]$} & 1.63 & {$[1.25-2.11]$} & 1.00 & {$[0.99-1.02]$} \\
\hline \multicolumn{7}{|l|}{ Behavioral components } \\
\hline Smoking & 1.64 & {$[1.25-2.11]$} & 1.66 & {$[1.27-2.15]$} & 0.99 & {$[0.96-1.01]$} \\
\hline Healthy diet & 1.64 & {$[1.25-2.11]$} & 1.65 & {$[1.23-2.16]$} & 0.99 & {$[0.93-1.06]$} \\
\hline Physical activity & 1.64 & {$[1.25-2.11]$} & 1.64 & {$[1.26-2.11]$} & 1.00 & {$[0.98-1.01]$} \\
\hline BMI & 1.64 & {$[1.25-2.11]$} & 1.62 & {$[1.23-2.10]$} & 1.01 & {$[0.96-1.07]$} \\
\hline \multicolumn{7}{|l|}{ Lower income $(N=5570)$} \\
\hline CVH score ${ }^{b}$ & 1.24 & {$[0.99-1.58]$} & 1.19 & {$[0.94-1.51]$} & 1.05 & {$[1.00-1.11]$} \\
\hline \multicolumn{7}{|l|}{ Components of $\mathrm{CVH}$ score } \\
\hline Biological components & 1.24 & {$[0.99-1.58]$} & 1.24 & {$[0.99-1.57]$} & 1.01 & {$[0.99-1.02]$} \\
\hline Behavioral components & 1.24 & {$[0.99-1.58]$} & 1.25 & {$[1.00-1.60]$} & 0.99 & {$[0.97-1.01]$} \\
\hline \multicolumn{7}{|l|}{ Biological components } \\
\hline Total cholesterol & 1.24 & {$[0.99-1.58]$} & 1.25 & {$[1.00-1.60]$} & 0.99 & {$[0.97-1.01]$} \\
\hline Blood pressure & 1.24 & {$[0.99-1.58]$} & 1.22 & {$[0.98-1.56]$} & 1.02 & {$[1.00-1.06]$} \\
\hline Fasting plasma glucose & 1.24 & {$[0.99-1.58]$} & 1.24 & {$[0.99-1.58]$} & 1.00 & {$[0.99-1.02]$} \\
\hline \multicolumn{7}{|l|}{ Behavioral components } \\
\hline Smoking & 1.24 & {$[0.99-1.58]$} & 1.24 & {$[0.99-1.58]$} & 1.00 & {$[0.99-1.01]$} \\
\hline Healthy diet & 1.24 & [0.99-1.58] & 1.25 & [1.00-1.59] & 0.99 & [0.97-1.01] \\
\hline Physical activity & 1.24 & [0.99-1.58] & 1.23 & [0.99-1.57] & 1.01 & [0.99-1.03] \\
\hline BMI & 1.24 & [0.99-1.58] & 1.24 & [0.99-1.58] & 1.00 & [0.98-1.02] \\
\hline
\end{tabular}

$H R$ hazard ratio; $C I$ confidence interval

The observed differences in total effects between table 2 and table 3 can be explained by the use of bootstraps for table 3

${ }^{a}$ Adjusted for age, gender, education (for income and occupation models), living alone (for income models), APOE4 and study centers

${ }^{\mathrm{b}}$ Global CVH score as a continous variable (total score range, 0-14) 
Table 4 Total, direct and indirect effects of socioeconomic level through non-fatal vascular events $\left(\mathrm{MSM}^{\mathrm{a}}\right.$ with inverse probability weighting)

\begin{tabular}{llll}
\hline & $\begin{array}{l}\text { Total } \\
\text { effect } \\
\text { HR }(95 \% \mathrm{CI})\end{array}$ & $\begin{array}{l}\text { Natural direct } \\
\text { effect } \\
\text { HR }(95 \% \mathrm{CI})\end{array}$ & HR $(95 \% \mathrm{CI})$ \\
\hline Primary education $\left(\mathrm{N}=5526^{\mathrm{b}}\right)$ & $1.37(1.08-1.73)$ & $1.36(1.08-1.72)$ & $1.00(0.88-1.14)$ \\
Blue-collar workers $\left(\mathrm{N}=5526^{\mathrm{b}}\right)$ & $1.63(1.25-2.12)$ & $1.64(1.26-2.14)$ & $1.01(0.86-1.16)$ \\
Lower income $\left(\mathrm{N}=5515^{\mathrm{b}}\right)$ & $1.16(0.92-1.47)$ & $1.16(0.92-1.47)$ & $1.00(0.88-1.15)$ \\
\hline
\end{tabular}

$H R$ hazard ratio; $C I$ confidence interval

${ }^{a}$ Adjusted for age, gender, education (for income and occupation models), living alone (for income models), APOE4 and study centers

b55 participants excluded due to extreme values for IPW
It is possible that CVD and CVH play a more important role in explaining SES-dementia inequalities when conceptualized in the middle-age period. It would be interesting in future analyses to explore such mechanisms in elderly cohorts with $\mathrm{CVH}$ documented in midlife or early aging and possibly identify age thresholds under which CVH and CVD play a more critical role in dementia inequalities. In addition, future studies are recommended to explore other potential underlying mechanisms such as environmental exposure or psychosocial factors (e.g., leisure activities, social interaction).

Our study has some limitations. First, our population sample is recruited in three French urban areas limiting the generalization of our results. There is another limitation regarding the association between vascular events and dementia in the $3 \mathrm{C}$ study. Usually, stroke has been shown to follow a social gradient with incidence rising as socioeconomic status decreases. However, in the $3 \mathrm{C}$ study, a higher level of household income was associated with a higher risk of ischemic stroke [47]. The selective survival hypothesis may provide a potential explanation. Moreover, in the 3C study, we have the ability to look at types of dementia. It would have been particularly interesting to conduct the mediation analysis only with mixed and vascular dementia cases, but we lacked the power to do this analysis ( $\mathrm{n}=91$ incident cases). Our major strengths include the large population sample with long follow-up and the active search to identify incident dementia cases and vascular events, validated by specific independent committees. We also used different decomposition approaches including weighting methods with IORW and marginal structural models in order to consider the two mediators of interests separately while accounting for their dependence. However, such analyses showed inconsistent and imprecise indirect effects.

\section{Conclusion}

The research on social determinants of health is particularly challenging due to the complexity of the causal pathways and the long time periods during which they play out [3], and this is especially true in dementia research as dementia is a multifactorial disease whose neurodegenerative process begins 20 to 30 years before the onset of the first clinical symptoms. In this context, causal mediation analysis can provide a better understanding of complex relationships quantifying the importance of each pathway and thereby allowing to identify potential prevention targets to successful ageing. Our findings highlighted $\mathrm{CVH}$ and vascular events play a limited role as mediator between SES and dementia.

Supplementary Information The online version contains supplementary material available at https://doi.org/10.1007/s10654-021-00788-8.

Acknowledgements Funding sources were not involved in the design or conduct of the study; collection, management, or analysis of the data; interpretation of the results; preparation, review, or approval of the manuscript; or decision to submit for publication.

Authors' contributions NL conceived study hypotheses, did statistical analysis, interpreted the results and edited the first draft of the manuscript. SDI helped to perform statistical modeling. AG contributed to data collection. CT and CB conceptualized and designed the study, recruited volunteers, contributed data and finding. JPE and CS helped interpret and discuss the results. TB conceived study hypotheses, helped perform statistical modeling and write the manuscript. All authors critically revised the manuscript.

Funding The 3C Study was conducted under a partnership agreement between the Institut National de la Santé et de la Recherche Médicale (INSERM), the Victor Segalen-Bordeaux II University and the Sanofi-Synthélabo Company. The Fondation pour la Recherche Médicale supported the preparation and initiation of the study. The 3C Study is also supported by the Caisse Nationale Maladie des Travailleurs Salariés, Direction Générale de la Santé, Conseils Régionaux of Aquitaine, Languedoc-Roussillon and Bourgogne, Fondation de France, Ministry of Research-INSERM Programme 'Cohortes et collections de données biologiques', Mutuelle Générale de l'Education Nationale, Institut de la longévité, Conseil Général de la Côte d'Or, Agence Nationale de la Recherche ANR PNRA 2006 (ANR/DEDD/PNRA/ PROJ/200206-01-01) and Longvie 2007 (LVIE-003-01) and Fonds de coopération scientifique Alzheimer (FCS 2009-2012).

Availability of data and materials Data are available on reasonable request. Anonymized data will be shared by request to the $3 \mathrm{C}$ scientific committee. 
Conflict of interest The authors declare that they have no conflict of interest.

Ethical approval The study protocol was approved by The Ethics Committees of the Hospital of Kremlin-Bicêtre and Sud-Méditerranée III.

Consent to participate All participants provided written consents for this study.

Open Access This article is licensed under a Creative Commons Attribution 4.0 International License, which permits use, sharing, adaptation, distribution and reproduction in any medium or format, as long as you give appropriate credit to the original author(s) and the source, provide a link to the Creative Commons licence, and indicate if changes were made. The images or other third party material in this article are included in the article's Creative Commons licence, unless indicated otherwise in a credit line to the material. If material is not included in the article's Creative Commons licence and your intended use is not permitted by statutory regulation or exceeds the permitted use, you will need to obtain permission directly from the copyright holder. To view a copy of this licence, visit http://creativecommons.org/licenses/by/4.0/.

\section{References}

1. Mackenbach JP, Stirbu I, Roskam A-JR, Schaap MM, Menvielle G, Leinsalu M, et al. Socioeconomic inequalities in Health in 22 European countries. N Engl J Med. 2008;358(23):2468-24681.

2. Stringhini S, Carmeli C, Jokela M, Avendaño M, Muennig P, Guida F, et al. Socioeconomic status and the $25 \times 25$ risk factors as determinants of premature mortality: a multicohort study and meta-analysis of 1.7 million men and women. The Lancet. 2017;389(10075):1229-37.

3. Braveman P, Gottlieb L. The social determinants of health: it's time to consider the causes of the causes. Public Health Rep. 2014;129(Suppl 2):19-31.

4. Resende EDPF, Llibre Guerra JJ, Miller BL. Health and socioeconomic inequities as contributors to brain health. JAMA Neurol. 2019;76(6):633-4.

5. Zeki Al Hazzouri A, Haan MN, Kalbfleisch JD, Galea S, Lisabeth LD, Aiello AE. Life-course socioeconomic position and incidence of dementia and cognitive impairment without dementia in older Mexican Americans: results from the Sacramento Area Latino Study on aging. Am J Epidemiol. 2011;173(10):1148-58.

6. Sharp ES, Gatz M. The relationship between education and dementia an updated systematic review. Alzheimer Dis Assoc Disord. 2011;25(4):289-304.

7. Karp A, Kåreholt I, Qiu C, Bellander T, Winblad B, Fratiglioni L. Relation of education and occupation-based socioeconomic status to incident alzheimer's disease. Am J Epidemiol. 2004;159(2):175-83.

8. Russ TC, Stamatakis E, Hamer M, Starr JM, Kivimäki M, Batty GD. Socioeconomic status as a risk factor for dementia death: individual participant meta-analysis of 86508 men and women from the UK. Br J Psychiatry. 2013;203(1):10-7.

9. Letellier N, Gutierrez L-A, Carrière I, Gabelle A, Dartigues J-F, Dufouil C, et al. Sex-specific association between neighborhood characteristics and dementia: The Three-City cohort. Alzheimers Dement. 2018;14(4):473-82.

10. Ouvrard C, Meillon C, Dartigues J-F, Tabue Teguo M, AvilaFunes JA, Amieva H. Psychosocioeconomic precariousness and frailty: the respective contribution in predicting mortality. J Frailty Aging. 2019;8(1):42-7.
11. Letellier N, Carrière I, Cadot E, Berkman L, Goldberg M, Zins M, et al. Individual and neighbourhood socioeconomic inequalities in cognitive impairment: cross-sectional findings from the French CONSTANCES cohort. BMJ Open. 2020;10(3):e033751.

12. Marden JR, Tchetgen Tchetgen EJ, Kawachi I, Glymour MM. Contribution of socioeconomic status at 3 life-course periods to late-life memory function and decline: early and late predictors of dementia risk. Am J Epidemiol. 2017;186(7):805-14.

13. Courtin E, Nafilyan V, Glymour M, Goldberg M, Berr C, Berkman LF, et al. Long-term effects of compulsory schooling on physical, mental and cognitive ageing: a natural experiment. J Epidemiol Community Health. 2019;73(4):370-6.

14. Staff RT, Murray AD, Ahearn TS, Mustafa N, Fox HC, Whalley LJ. Childhood socioeconomic status and adult brain size: childhood socioeconomic status influences adult hippocampal size. Ann Neurol. 2012;71(5):653-60.

15. Ngandu T, von Strauss E, Helkala E-L, Winblad B, Nissinen A, Tuomilehto J, et al. Education and dementia: what lies behind the association? Neurology. 2007;69(14):1442-50.

16. Cummings JL, Tong G, Ballard C. Treatment combinations for alzheimer's disease: current and future pharmacotherapy options. J Alzheimers Dis. 2019;67(3):779-94.

17. Janković S, Stojisavljević D, Janković J, Erić M. Marinković J (2014) Association of socioeconomic status measured by education, and cardiovascular health: a population-based crosssectional study. BMJ Open. 2014;4(7):e005222.

18. Marmot MG, Bosma H, Hemingway H, Brunner E, Stansfeld S. Contribution of job control and other risk factors to social variations in coronary heart disease incidence. Lancet. 1997;350(9073):235-9.

19. Clark AM, DesMeules M, Luo W, Duncan AS, Wielgosz A. Socioeconomic status and cardiovascular disease: risks and implications for care. Nat Rev Cardiol. 2009;6(11):712-22.

20. Lynch JW, Kaplan GA, Cohen RD, Tuomilehto J, Salonen JT. Do Cardiovascular risk factors explain the relation between socioeconomic status, risk of all-cause mortality, cardiovascular mortality, and acute myocardial infarction? Am J Epidemiol. 1996;144(10):934-42.

21. Willette AA, Bendlin BB, Starks EJ, Birdsill AC, Johnson SC, Christian BT, et al. Association of insulin resistance with cerebral glucose uptake in late middle-aged adults at risk for alzheimer disease. JAMA Neurol. 2015;72(9):1013-20.

22. Power MC, Schneider ALC, Wruck L, Griswold M, Coker LH, Alonso A, et al. Life-course blood pressure in relation to brain volumes. Alzheimers Dement. 2016;12(8):890-9.

23. Weinstein G, Maillard P, Himali JJ, Beiser AS, Au R, Wolf $\mathrm{PA}$, et al. Glucose indices are associated with cognitive and structural brain measures in young adults. Neurology. 2015;84(23):2329-37.

24. Wagner M, Helmer C, Tzourio C, Berr C, Proust-Lima C, Samieri C. Evaluation of the concurrent trajectories of cardiometabolic risk factors in the 14 years before dementia. JAMA Psychiat. 2018;75(10):1033-42.

25. Samieri C, Perier M-C, Gaye B, Proust-Lima C, Helmer C, Dartigues J-F, et al. Association of cardiovascular health level in older age with cognitive decline and incident dementia. JAMA. 2018;320(7):657-64.

26. Deckers K, Schievink SHJ, Rodriquez MMF, van Oostenbrugge RJ, van Boxtel MPJ, Verhey FRJ, et al. Coronary heart disease and risk for cognitive impairment or dementia: Systematic review and meta-analysis. PLoS ONE. 2017;12(9):e0184244.

27. Kuźma E, Lourida I, Moore SF, Levine DA, Ukoumunne OC, Llewellyn DJ. Stroke and dementia risk: a systematic review and meta-analysis. Alzheimers Dement. 2018;14(11):1416-26.

28. Nakahori N, Sekine M, Yamada M, Tatsuse T, Kido H, Suzuki M. A pathway from low socioeconomic status to dementia in 
Japan: results from the Toyama dementia survey. BMC Geriatr. 2018;18(1):102.

29. Deckers K, Cadar D, van Boxtel MPJ, Verhey FRJ, Steptoe A, Köhler S. Modifiable risk factors explain socioeconomic inequalities in dementia risk: evidence from a population-based prospective cohort study. J Alzheimers Dis. 2019;71(2):549-57.

30. 3C Study Group. Vascular factors and risk of dementia: design of the three-city study and baseline characteristics of the study population. Neuroepidemiology 2003;22(6):316-25.

31. Lloyd-Jones DM, Hong Y, Labarthe D, Mozaffarian D, Appel LJ, Van Horn L, et al. Defining and setting national goals for cardiovascular health promotion and disease reduction: the American Heart Association's strategic Impact Goal through 2020 and beyond. Circulation. 2010;121(4):586-613.

32. Straczek C, Ducimetiere P, Barberger-Gateau P, Helmer C, Ritchie $\mathrm{K}$, Jouven $\mathrm{X}$, et al. Higher level of systemic C-reactive protein is independently predictive of coronary heart disease in older community-dwelling adults: the three-city study. J Am Geriatr Soc. 2010;58(1):129-35.

33. Bineau S, Dufouil C, Helmer C, Ritchie K, Empana J-P, Ducimetière $\mathrm{P}$, et al. Framingham stroke risk function in a large population-based cohort of elderly people: the $3 \mathrm{C}$ study. Stroke. 2009;40(5):1564-70.

34. Lange T, Hansen JV. Direct and indirect effects in a survival context. Epidemiol. 2011;22(4):575-81.

35. Aalen O. A model for nonparametric regression analysis of counting processes. In: Klonecki W, Kozek A, Rosiński J, editors. Mathematical statistics and probability theory. New York: Springer; 1980. p. 1-25.

36. Hernán MA, Robins JM. Causal Inference: what If. Boca Raton: Chapman \& Hall/CRC; 2020. p. 149-58.

37. VanderWeele TJ. Mediation analysis: a practitioner's guide. Annu Rev Public Health. 2016;37:17-32.
38. Hafeman DM, Schwartz S. Opening the black box: a motivation for the assessment of mediation. Int J Epidemiol. 2009;38(3):838-45.

39. Oakes JM, Kaufman JS. Methods in social epidemiology. Wiley; 2017.

40. Tchetgen Tchetgen EJ. Inverse odds ratio-weighted estimation for causal mediation analysis. Stat Med. 2013;32(26):4567-80.

41. Nguyen QC, Osypuk TL, Schmidt NM, Glymour MM, Tchetgen Tchetgen EJ. Practical guidance for conducting mediation analysis with multiple mediators using inverse odds ratio weighting. Am J Epidemiol. 2015;181(5):349-56.

42. VanderWeele T. Explanation in causal inference: methods for mediation and interaction. Oxford University Press; 2015. p. 729.

43. Weele TJV. Brief report: concerning the consistency assumption in causal inference. Epidemiology. 2009;20(6):880-3.

44. Rehkopf DH, Glymour MM, Osypuk TL. The consistency assumption for causal inference in social epidemiology: when a rose is not a rose. Curr Epidemiol Rep. 2016;3(1):63-71.

45. Farah MJ. The neuroscience of socioeconomic status: correlates, causes, and consequences. Neuron. 2017;96(1):56-71.

46. Moriguchi Y, Shinohara I. Socioeconomic disparity in prefrontal development during early childhood. Sci Rep. 2019;9(1):1-8.

47. Grimaud O, Dufouil C, Alpérovitch A, Pico F, Ritchie KA, Helmer $\mathrm{C}$, et al. Incidence of ischaemic stroke according to income level among older people: the 3C study. Age Ageing. 2011;40(1):116-21.

Publisher's Note Springer Nature remains neutral with regard to jurisdictional claims in published maps and institutional affiliations. 